\title{
LA PARTICIPACIÓN DEL CONDE DE CAMPO ALANGE EN EL ARTISTA EN LOS TRES PRIMEROS MESES DE 1835
}

\author{
María José AlOnSO SEOANE \\ aseoane@ccinf.ucm.es \\ Universidad Complutense de Madrid
}

\section{Resumen}

En el Archivo de los Condes de Campo de Alange se encuentran actualmente manuscritos autógrafos relacionados con El Artista correspondientes a los tres primeros meses de 1835. Este trabajo se centra en la participación desconocida de José de Negrete, conde de Campo Alange, en la redacción de El Artista y la vida interna de la publicación en sus orígenes, a través de los manuscritos conservados en el Archivo.

Palabras clave: José de Negrete, Conde de Campo Alange, El Artista, Eugenio de Ochoa, Romanticismo español, Literatura y periodismo

\begin{abstract}
In the Archive of the Condes de Campo de Alange there currently are autograph manuscripts related to El Artista, which were written in the first three months of 1835 . This work focuses on the unknown participation of José de Negrete, Conde de Campo Alange, in the drafting of El Artista and the internal life of the publication in its origins, through the manuscripts preserved in the Archive.
\end{abstract}

Keywords: José de Negrete, conde de Campo Alange, El Artista, Eugenio de Ochoa, Spanish Romanticism, Literature and journalism 


\section{La actividad desconocida del conde de Campo Alange en los primeros meses de El Artista}

Como suele suceder en publicaciones análogas, los tres primeros meses de la vida de El Artista, marcan el programa de la revista y constituyen la base de consolidación de su identidad, para sus creadores y para el público. Estas primeras entregas incluyen, además de la parte gráfica de estampas litografiadas de diverso carácter, la conocida distribución de El Artista en distintas secciones que, en resumen, abarcan artículos sobre biografías de ingenios españoles, bellas artes, literatura y textos de creación, que aparecen firmados con un moderno sentido de autoría; así como escritos de carácter editorial, reseñas y comentarios de actualidad cultural. Aunque las colaboraciones son obviamente esenciales para el estudio de la revista, tienen también un interés particular los textos no firmados, que hacen referencia a la vida interna de la revista y a aspectos de actualidad. Estos textos tienen mayor fluidez que los enmarcados en las demás secciones y están más relacionados con la continua conversación de la vida social, especialmente, en el debate entre las distintas publicaciones periódicas de la época en que El Artista participa. De esta manera, los textos no firmados de carácter circunstancial, como Advertencias, Variedades, crónica de teatros y otros acontecimientos culturales de la semana, contribuyen a un mejor conocimiento de lo que El Artista era y suponía, de hecho, en el momento de su publicación.

En general, se ha dado por supuesto que Eugenio de Ochoa, como principal artífice de El Artista, sería el autor de los textos no firmados, ya que no se había podido advertir el papel que José de Negrete y Cepeda, V conde de Campo de Alange (1812-1836), conocido por sus importantes colaboraciones de creación y crítica, tenía en la revista como editor literario; a pesar de que, en la época, distintos testimonios lo señalan como fundador y director de la revista ${ }^{1}$. Sin embargo, como adelanté en alguna ocasión (Alonso Seoane

1. El propio Eugenio de Ochoa, al recordar a su amigo: «Juntos fundamos con Federico de Madrazo el Artista» (Ochoa 1867, pág. 274) y Joaquín Ignacio Mencos, entonces barón de Bigüezal, amigo de Campo Alange, que se preocuparía más tarde por su sepultura (Archivo de los Condes de Campo de Alange -ACCA, en lo sucesivo al indicar la signatura de los manuscritos- 53.017) (Mencos y Manso de Zúñiga 1952, pág. 107). Actualizo ortografía y puntuación en los textos impresos de época; en las citas de textos publicados en El Artista indico, entre paréntesis, tomo y página. Además de las conocidas obras sobre El Artista (Simón Díaz 1946; Calvo Serraller y González García 1981), el interés por la revista se muestra en estudios de carácter general sobre el Romanticismo en España, así como en trabajos monográficos, más cercanos en el tiempo, que se ocupan de la revista desde distintos ángulos (Lozano Miralles 1988; López Sanz 2000; Alonso Seoane 2002; Ayala Aracil 2002; Ferri Coll 2011; Rodríguez Gutiérrez 2011). 
2011 a, pág. 308 y 2011b), gracias a la existencia de un fondo de manuscritos relacionados con El Artista en el Archivo de los condes de Campo de Alange, actualmente puede probarse la participación de José de Negrete en aspectos decisivos de la revista. En este caso, en los momentos iniciales de la publicación, ya que, en principio, los documentos conservados —originales autógrafos de textos publicados en El Artista, cartas y otros escritos-, corresponden al periodo comprendido entre enero y marzo de 1835. Entre otros aspectos de gran interés, estos manuscritos ponen de manifiesto la parte esencial que tuvo Campo Alange, mano a mano con Ochoa, en cuanto a los textos no firmados y las notas indicativas de las relaciones con la imprenta para la edición de El Artista, tareas que corresponden en exclusiva a Ochoa y Campo Alange, lo que nos permite atisbar la vida interna de la redacción de la revista en sus comienzos².

No es posible tratar aquí en detalle el contenido del fondo documental, que será objeto de estudios particulares. En este artículo nos centraremos en los textos no firmados con objeto de dar noticia de los mismos y señalar el alcance del papel de Campo Alange en esta etapa de El Artista; dejando para otra ocasión, junto con la de los textos de creación y crítica de Campo Alange, su edición y estudio, aspectos que exceden de los límites de este artículo ${ }^{3}$.

\section{Los manuscritos relativos a El Artista en el Archivo de los condes de Campo de Alange}

Aunque no es posible conocer con exactitud las vicisitudes de los textos desde su creación, sí conocemos la fecha exacta en que María Manuela de Negrete y Cepeda (1809-1883), hermana mayor de José de Negrete y, a su muerte, vi condesa de Campo de Alange, ordenó los manuscritos de su hermano

2. Además de otra documentación del mayor interés, como cartas de Ochoa y Campo Alange que conocemos por la transcripción de la conferencia que pronunció doña María Laffite y Pérez del Pulgar en el Museo Romántico, el 16 de enero de 1954, de la que se conserva el texto inédito, en cuartillas mecanografiadas (ACCA 65.010046); y otras publicaciones en que se hacen referencias a distintos materiales originales (Mencos 1952; Saltillo 1931). A estas referencias hay que anadir recientes descubrimientos que pueden completar lo que existe en ACCA, que serán objeto de una futura publicación, con la edición de los textos y diferentes estudios monográficos, coordinada por Pedro Rodríguez-Ponga y Salamanca.

3. Como en ocasiones anteriores, agradezco a Dña. Almudena de Salamanca y Suelves, condesa de Campo de Alange y D. Francisco Javier Castellano Barón, conde de Nieva, IX condes de Campo de Alange, la amabilidad y generosidad con que me han facilitado el trabajo de archivo y la publicación de los resultados. Agradezco también de manera especial el apoyo constante del Dr. Enrique Rubio Cremades, que me escuchó hablar de este tema por primera vez en noviembre de 2002.

Anales, 25, 2013, pp. 11-43 
conservados en el Archivo, anotando en una hoja suelta, doblada en cuatro como para servir de etiqueta: «Composiciones, y traducciones del Sr. D. José Negrete/ 11 de Mayo de 1869». Este texto se repite, escrito con mayor intimidad y con alguna variante, en el dorso de una de las cuartillas dobladas que corresponden a parte del original del texto de Campo Alange, «Recuerdos del sitio de la ciudadela de Amberes», a modo de portada: «Composiciones, traducciones de mi hermano/ 11 de Mayo de 1869» (ACCA 66.089022).

No sería extraño que los manuscritos de las obras literarias de Campo Alange, fallecido trágicamente en la guerra carlista, se conservaran entre sus papeles, pero la existencia de otros textos relacionados con los primeros números de El Artista, hace suponer que la redacción de la revista en esta etapa estuvo instalada en el domicilio de Campo Alange, en el $n^{\circ} 2$ de la calle Duque de Alba, en las fechas que corresponden al periodo en que Campo Alange está en Madrid, en un intervalo de su actividad bélica: desde finales de enero de 1835 a principios de abril del mismo año, en que sale de Madrid para visitar sus posesiones de Extremadura y, posteriormente, viajar por Andalucía y Gibraltar (Alonso Seoane 2011a), en un dilatado recorrido que dura todo el verano (Rodríguez-Ponga y Salamanca 2012, pág. 589). A partir de finales de marzo de 1835, coincidiendo con las últimas fechas en que pueden encontrarse manuscritos relacionados con El Artista en el Archivo, la redacción debió de trasladarse del domicilio de Campo Alange al Tívoli, el domicilio de los Madrazo en el Prado; sede entonces del Real Establecimiento Litográfico, donde se imprimían las estampas de El Artista, y donde, en general, se redactaría la revista, excepción hecha de este primer trimestre de 1835 en su conjunto.

El domicilio de los Madrazo habría sido ya el lugar donde, a comienzos del verano 1834, se preparó el primer número de la revista, que se estaba gestando desde la primavera del mismo año (González López y Martí Ayxelà 2007, pág. 26). Aunque sigue atentamente la aparición de El Artista, Campo Alange no está en Madrid en los meses en que Ochoa y Madrazo gestionan el proceso de publicación de la revista, con la solicitud de impresión el 17 de junio (Romero Tobar 1975, pág. 474), la redacción del prospecto y la preparación del primer número para su publicación el 6 de julio de 1834; publicación que, como es sabido, tuvo que retrasarse indefinidamente (Randolph 1966, pág. 15), en un panorama político muy difícil, como Ochoa expone a Campo Alange en carta de 26 de julio de 1835, señalando su incertidumbre sobre la salida de El Artista (Laffite y Pérez del Pulgar 1946, pág. 21) ${ }^{4}$. Meses después,

4. Aunque en este artículo se da por destino de las cartas Sevilla, Pedro Rodríguez-Ponga lo sitúa en Burgos: «Debió pasar aquí una larga temporada, quizá con algún viaje intermedio a Madrid, pero no a Sevilla como se ha solido creer erróneamente» (Rodríguez-Ponga 
a finales de 1834, en el domicilio de los Madrazo se pondrá a punto la primera entrega de El Artista para su salida definitiva el 4 de enero de $1835^{5}$. Con toda probabilidad, como veremos, también las dos siguientes, correspondientes al 11 y 18 de enero, así como las demás, después de la partida de Madrid de Campo Alange a Extremadura en abril de 1835, hasta el final de la publicación de El Artista, el 27 de marzo de 1836; siendo, por tanto, su lugar habitual de redacción (Zorrilla 1880, t. I, pág. 21).

Del primer número de El Artista, tan accidentado, sólo ha quedado en el Archivo el original correspondiente de los «Recuerdos del sitio de la ciudadela de Amberes por los franceses en 1832», del propio Campo Alange, cuyo manuscrito muestra correcciones de su mano y algunas advertencias para la imprenta, además de la anotación escrita por su hermana, indicada arriba. Desde esta $1^{a}$ entrega a la $12^{a}$ inclusive, correspondientes a los domingos correlativos del 4 de enero al 22 de marzo de 1835, como indicaremos de manera detallada, se conservan en el Archivo, en diverso estado, los manuscritos autógrafos de un número considerable de originales de los textos que componen las entregas, así como otros documentos — cartas y borradores diversos- que, como apuntamos, indican que, en fechas próximas, el lugar de redacción de El Artista, se habría trasladado del domicilio de los Madrazo al de Campo Alange. Esto no sería antes de que Campo Alange, incorporado al ejército del Norte desde antes de la salida del primer número de El Artista, el 4 de enero de 1835, estuviera de nuevo en Madrid, a finales de este mes. De hecho, tampoco se conserva ningún manuscrito correspondiente a textos publicados en las dos siguientes semanas de El Artista, salvo los escritos por Campo Alange —el comienzo de los «Recuerdos de Amberes», ya citado, con

y Salamanca 2012, pág. 586). Ochoa trata también la situación en otra de sus cartas a Campo Alange, recogida por María Laffite y Pérez del Pulgar en el texto de su conferencia (ACCA 65.010046). A finales de marzo, Campo Alange publica su último artículo sobre la Milicia Urbana en La Revista Española (23-3-1834), y fecha una primera disposición testamentaria en Madrid, el 27 de marzo de 1834, antes de reincorporarse al ejército (ACCA 66.076001-4).

5. Véase la nota que escribe Ochoa a Santiago de Masarnau (Archivo Histórico Nacional, DIVERSOS-COLECCIONES, 6, N. 30), que transcribe José Simón Díaz (1946, pág. 30); sin fecha, pero de finales de diciembre de 1834 o muy a principios de enero de 1835 (las representaciones de Don Giovanni, que reseña Masarnau, tuvieron lugar los días 21 y 23 de diciembre de 1834).

6. El comienzo de la serie (la introducción, sin título, y el Fragmento I, «El viaje»), correspondiente a la $1^{a}$ entrega de El Artista. De los «Recuerdos del sitio de la ciudadela de Amberes», solo se conservan actualmente en el Archivo, además de la introducción y el Fragmento I, el Fragmento II y el Fragmento VII y último (ACCA 66.089001-44).

Anales, 25, 2013, pp. 11-43 
los Fragmentos I y II, y el artículo «A la Aristocracia española»-, que seguramente había dejado a Ochoa antes de su marcha.

A través de la correspondencia de Campo Alange con su administrador, don Juan de la Torre y Rújula, que se conserva en el Archivo, es posible seguir algunos de los movimientos de Campo Alange por estas fechas, en una secuencia que va desde comienzos hasta mediados de enero de 1835. El viernes 2 de enero de 1835, ya inminente la salida de El Artista, Campo Alange está en Burgos, desde donde escribe a su administrador (ACCA 66.030029-31), de paso hacia Vitoria, donde encontrará dificultades de alojamiento al estar la ciudad colapsada por las fuerzas concentradas en ella. Desde Vitoria escribe de nuevo a su administrador el día 11 (ACCA 66.030032-3) y el 15 (ACCA $66.030035-7)^{7}$. A su vez, el 16 de enero, el administrador escribe la última carta del periodo, contestando a la de Campo Alange del día 11; carta que se cruza con la anteriormente citada de Campo Alange, de 15 de enero, en que habla de la inminencia de su entrada en acción ${ }^{8}$. A partir de esta fecha se interrumpe la correspondencia con Contaduría que no se reanuda hasta meses más tarde, cuando Campo Alange está de viaje por Extremadura. Esta interrupción coincide con el regreso de Campo Alange a Madrid, que hace innecesaria la correspondencia.

En cualquier caso, Campo Alange está en Madrid, con seguridad, al menos desde el jueves 22 de enero, en que asiste, «a las seis y media de la noche», según la hora anunciada en el Diario de Avisos de Madrid del mismo día, a la representación de La vida es sueño en el teatro de la Cruz; sobre la que publica una reseña el domingo siguiente, 25 de enero, en la entrega $n^{\circ} 4$ de El Artista, cuyo original autógrafo se encuentra entre los manuscritos conservados en el Archivo (ACCA 66.092003-7). A partir de esta entrega 4a ${ }^{a}$, que se abre con una «Advertencia» escrita por Campo Alange sobre los criterios de la revista sobre

7. En esta última carta, escribe: «Estimado Rújula: Mañana nos ponemos en movimiento con el fin de atacar decididamente a los facciosos [...]. Si nos esperan, pasado mañana será día caliente» (ACCA 66.030035). Campo Alange facilita la dirección de don Justo Barañez [Pintorería 25], que ha dado alojamiento a su criado Pepe, enfermo de pulmonía, y también a él. Salvo error por mi parte, se trata de José Menéndez, al que recuerda especialmente en «Mi última voluntad», firmada en Portugalete, el 30 de noviembre de 1836 (copias en ACCA 53.018002-3 y 66.005001-2, e inventario de las alhajas que le dejó en su última disposición, en ACCA 66.023001).

8. A los dos días, bajo el mando del general Manuel Lorenzo tuvo lugar la acción de Orbiso. Posiblemente, sería después cuando Campo Alange, siempre mal de salud desde su primera incorporación al ejército, vuelve a Madrid para iniciar un prolongado descanso —un Madrid en seria alarma por los sucesos del 18 de enero-. 
posibles comunicados de sus lectores (ACCA 66.092008-9), Campo Alange participará directamente en la dirección y redacción de El Artista hasta, al menos, la entrega ${ }^{\circ} 12$ (22-3-1835), última de la que quedan originales manuscritos en el Archivo.

En cuanto a otro tipo de documentos relacionados con El Artista, de fecha muy cercana se conserva una carta del ingeniero Epifanio Esteban, datada en Valladolid, el 21 de enero de 1835, que es respuesta a otra de Campo Alange que no pudo haber sido muy anterior. En ella, Esteban acepta la invitación que le ha hecho Campo Alange a colaborar en El Artista, sugiriendo algunos temas posibles que se compromete a explanar, si a Campo Alange «y a los Redactores les agradan» (ACCA 65.026001-2). También asegura que procurará enterarse de los datos relevantes sobre el castillo de Fuensaldaña y los cuadros atribuidos a Rubens del convento de monjas del mismo lugar, por los que Campo Alange ha manifestado interés; adelantando alguna de las ideas que aparecerán en el artículo «Fuensaldaña», de Campo Alange, publicado el 15 de febrero siguiente en el $n^{\circ} 7$ de El Artista (I, 73-4).

No todas las cartas y colaboraciones relacionadas con la redacción de El Artista que se conservan en el Archivo están fechadas, pero cabe suponer que corresponden, como los demás documentos, a los tres primeros meses de 1835. Cuando se trata de colaboraciones publicadas en la revista, resulta fácil la localización temporal del texto, a veces, con margen de pocos días, como ocurre con el «Soneto» autógrafo de Francisco de Laiglesia y Darrac, «En la muerte del General D. Manuel Freire, acaezida en esta Corte, el día 7 del corriente mes» (ACCA 66.086001), que fue publicado días después en la entrega $^{\circ} 11$ de El Artista, correspondiente al 15 de marzo de 1835 (I, 132). Con respecto a otros manuscritos que permanecieron inéditos, sólo por excepción se conoce la fecha de remisión de uno de ellos: una carta del marqués de San Felices - Mariano Guillamas y Galiano- dirigida a Campo Alange con fecha de 17 de febrero de 1835, en que le recomienda la publicación de una «Oda», escrita por un joven principiante, cuyo texto adjunta (ACCA 66.077)9.

9. La «Oda», fechada el 25 de septiembre de 1834, está dedicada «Al Exmo. Señor Marques de S. Felices con motivo de la muerte de su Esposa D ${ }^{a}$ Cesarea Castañon»; su autor es Juan Pedro de Espinosa [de los Monteros] y Cutillas (ACCA 66.077). Además de estas cartas, se conservan en ACCA algunos textos de distinto carácter, remitidos a Campo Alange o a los redactores de El Artista, y borradores incompletos; textos sin identificar que, en otra ocasión, trataremos por extenso: «A los edictores del Artista. Quintillas» (ACCA 66.081); un breve poema encabezado por la cita «Prêt a partir pour les rives du Tage...» (ACCA 66.092054); un relato incompleto que comienza «Quién será ese paladín» (ACCA 66.092054); y un artículo, incompleto, «Reflexiones sobre el estado actual del teatro en Francia» (ACCA 66.09297-9). Habría que añadir a estos papeles, entre

Anales, 25, 2013, pp. 11-43 


\section{Las colaboraciones de Campo Alange en El Artista después de marzo de 1835}

La intensa participación de Campo Alange en los tres primeros meses de El Artista, finaliza bruscamente con la última entrega de marzo, no 13 (29-31835). A pesar de que la presencia de Campo Alange es esencial en esta entrega, no existe actualmente en el Archivo ningún original de los artículos publicados en ella. En los meses siguientes, fuera ya del periodo del que se conservan manuscritos relacionados con El Artista, solo conocemos la actividad de Campo Alange por los textos que aparecen firmados; que, aunque muestran una menor intervención, indican que el interés de Campo Alange por El Artista no decayó a lo largo del tiempo, aunque las circunstancias de su vida limitaran su participación ${ }^{10}$.

En estas colaboraciones posteriores a marzo de 1835, se distinguen dos etapas claramente diferenciadas. La primera, cercana al primer trimestre de El Artista, corresponde a la estancia de Campo Alange en Extremadura, desde donde envía una nota sobre un mosaico romano recientemente descubierto, que aparece en el texto impreso sin título ni firma, poco después de su marcha en abril de 1835. La conocida nota se inserta en el n 18 de El Artista, correspondiente al 3 de mayo de 1835 (I, 215-6), con un encabezamiento ${ }^{11}$, escrito seguramente por Ochoa, que interpreta libremente el viaje de Campo Alange según el programa de El Artista de buscar y dar a conocer antigüedades dispersas por España (Alonso Seoane 2011a, pág. 313).

Pasado el verano, Campo Alange inicia una segunda etapa de colaboraciones en El Artista, que una nueva incorporación al ejército, a finales de diciembre de 1835, iba a truncar de forma definitiva. Poco después de su vuelta a Madrid en septiembre de 1835, a partir de su reciente experiencia, Campo Alange comienza la publicación de un importante texto de viajes, «Sevilla», en el n ${ }^{\circ} 15$ de El Artista el 11 de octubre de 1835, que, después de varias entregas, finaliza en el no 21, el 22 de noviembre de 1835 (Alonso Seoane 2001). Sin duda, por entonces, Campo Alange volvería a trabajar de cerca con Ochoa

otros que puedan aparecer, la carta dirigida al conde de Campo Alange por una supuesta «Julia», transcrita por el marqués del Saltillo (Saltillo 1931, pág. 137).

10. En la ordenada relación que hace Campo Alange de distintos objetos que llevará en campaña, anota, entre otros, útiles para dibujar (caja de pinturas, pinceles, lápices ingleses, cortaplumas, etc., «Sitio de Ambéres»); y, entre los libros, «Algs artistas» (ACCA 66.016001-2).

11. «Uno de nuestros colaboradores, el Sr. C. de C. A., que se halla actualmente recorriendo la Extremadura en busca de curiosidades artísticas, nos escribe de Mérida lo siguiente». El título y la firma sí aparecen en el Índice: «Antigüedades de Mérida. C. A» 
en la redacción de la revista; aunque, como señalamos, en este periodo no es posible determinar el grado de su intervención, salvo en el caso de las colaboraciones firmadas: la ya citada «Sevilla», y las Variedades que aparecen en la entrega 21 a (22-11-1835). Estas Variedades están formadas por dos breves artículos que Campo Alange firma, cada uno de ellos, con sus iniciales ( C . A.»). El primer texto es un comentario de actualidad, sobre el espectáculo circense que se está representando esos días en Madrid; en el que Campo Alange, además de hacer una admirativa reseña, detallada y divertida - especialmente, sobre las habilidades de su pallaso predilecto, Mr. Ratel (II, 251) evoca experiencias autobiográficas de cuando, tiempo atrás, tuvo ocasión de contemplar a algunos de los que ahora están actuando ${ }^{12}$.

La segunda «Variedad», de muy distinto carácter, está orientada hacia la modernización de la cultura en España, con la censura de enseñanzas obsoletas, que también Ochoa había denunciado en alguna ocasión en El Artista (I, 124). Campo Alange espera verlas desaparecer, ahora que recientemente —en alusión a la Real Orden de 3 de octubre de 1835 - se había prohibido el traje talar de los universitarios, símbolo de atraso intelectual. A pesar de que Campo Alange promete ampliar su crítica - ya que la manifestación de alguno de estos abusos daría materia «para largos e interesantes artículos» (II, 252), lo que supone una intención evidente de continuidad-, no volvió a colaborar en El Artista, por sus circunstancias personales y por el fin de la publicación. Campo Alange se reincorporó una vez más al ejército, ausentándose de Madrid el 24 de diciembre de 1835 para pasar unos días en Burgos, antes de presentarse en Vitoria, el 8 de enero de 1836 (Rodríguez-Ponga y Salamanca 2012, págs. 587-8); ya no volvería a Madrid antes de la desaparición de El Artista, en marzo de 1836.

Sin embargo, antes de su marcha, Campo Alange estuvo presente y, con seguridad, tomó parte en la decisión de seguir adelante con El Artista más allá de diciembre de 1835. El Artista, siempre en peligro de perecer por su cometido artístico y literario, especialmente en circunstancias de guerra ${ }^{13}$, pasa entonces por un momento crítico, en que sus creadores estuvieron a punto de finalizar su publicación al terminar el año, como se indica en la «Advertencia»

12. En la compañía de los «yernos de Franconi», Paul y Bastien —como se les nombra en uno de los anuncios del Diario de Avisos de Madrid (18-11-1835)—, a los que Campo Alange declara haber visto actuar anteriormente. Corrijo una errata no advertida en El Artista, «Tranconi» por «Franconi» (II, 250).

13. De las dificultades económicas para la existencia de periódicos culturales, a pesar del desinterés de los redactores que solo aspiran a cubrir gastos — sin duda, parece referirse al caso de El Artista-, da fe, entre otros testimonios, la Floresta Española ( $\mathrm{n}^{\circ} 14$, 4-4-1835, p. 54 y no $^{\circ} 19,7-5-1835$, p. 74).

Anales, 25, 2013, pp. 11-43 
que se inserta el 20 de diciembre de $1835^{14}$. A pesar de todo, se decide su continuidad para el siguiente año aunque, como es sabido, no pudo mantenerse más que un trimestre, con el cierre definitivo el 27 de marzo de 1836.

\section{La estrecha colaboración Eugenio de Ochoa y Campo Alange en la primera etapa de El Artista}

Antes de comenzar la relación detallada de los textos no firmados publicados en El Artista por Campo Alange y Ochoa, haremos alguna observación sobre los manuscritos, de éstos y otros autores, que, con notables diferencias en cuanto a número de originales conservados de las distintas entregas y el estado de los mismos, se conservan en el Archivo de los condes de Campo de Alange.

En primer lugar, obviamente, el contenido del Archivo, en su conjunto, tiene el mayor interés para el estudio del conde de Campo Alange y su obra. Además de otro tipo de documentación, como cartas, notas y textos sobre la guerra de Navarra, en cuanto a los artículos firmados por Campo Alange en El Artista, se conservan actualmente, en distinto estado de completitud, y con más o menos anotaciones o correcciones, los fragmentos ya citados de «Recuerdos del sitio de la ciudadela de Amberes por los franceses en $1832 »^{15}$, «A la aristocracia española», «Del drama moderno en Francia», «Teatro. II», «El último día de un reo de muerte. Por Victor Hugo», y el final de «Pamplona y Elizondo» (IV-VII). Entre los textos de Campo Alange publicados sin firma, que veremos con detalle, se conservan la «Advertencia» sobre posibles Comunicados («Al fundar el Artista [...]»), numerosos textos correspondientes a Variedades, y dos breves artículos: el que se publica con el título «La vida es sueño» (Rodríguez-Ponga y Salamanca 2012, pág. 589), y el que, sin título, trata sobre la edición de tres comedias de Tirso de Molina en Talía Española, por Agustín Durán. Ambos textos, como señalaremos, estaban destinados a Variedades según los manuscritos correspondientes, aunque no aparecen como tales al pasar al texto impreso.

14. «Sabemos que han corrido últimamente algunos rumores entre las pocas personas que tienen á bien honrar nuestros trabajos con su atención, de que iba a suspenderse el Artista a fin del presente año. Pudieron en efecto estos rumores no ser del todo infundados, pues a nadie ocultamos nuestra intención de poner fin a una empresa que tan poco en armonía está con las calamidades de estos tiempos; pero nos han hecho por fin variar de opinión [...] las repetidas pruebas de aprecio e interés que continuamente estamos recibiendo de personas cuya opinión respetamos mucho [...]» (II, 289).

15. La introducción y los Fragmentos I-II, y VII. Además de los textos, se conservan algunos dibujos sobre el sitio hechos por Campo Alange (ACCA 65.009002-9). 
El fondo existente en el Archivo que corresponde a Eugenio de Ochoa, de cuya mano, ocasionalmente, aparecen algunas correcciones en manuscritos ajenos, tiene el mayor interés, como podría esperarse. Se conservan, en todo o en parte, los originales de «A un niño», «A Grecia», «Contestación» «De la rutina», «El castillo del Espectro», «Zenobia» «Museo de pintura» «Calderón». «R. Museo de Pintura y Escultura de Madrid», «Poesías de Juan Bautista Alonso», «Don José Álvarez», «El Yadeste», «La estatua de Memnon»—que aparece sin firma en El Artista, pero no en el manuscrito del original, de letra de Ochoa, que firma «E. de O.»-, y un breve artículo, «Los contrastes», sobre la situación de Polonia, que quedó inédito. Un caso curioso lo constituye el original no firmado del «Diálogo entre don Pánfilo y don Timoteo sobre el revoque de las casas», escrito en horizontal en cuartillas numeradas, en que el comienzo es de letra que no hemos podido identificar, con algunas correcciones de Ochoa, hasta que sigue escribiendo Ochoa directamente en las cuartillas 6 y 7 , en que termina ${ }^{16}$.

\section{La actividad del conde de Campo Alange en los textos no firmados}

La participación de Campo Alange en los textos no firmados en los tres primeros meses de El Artista puede verse a través de los manuscritos conservados en el Archivo. Todos pertenecen, salvo la «Advertencia» inicial del no 4 de El Artista (25-1-1835) sobre Comunicados de los lectores, a la sección de Variedades y textos análogos que, en algún caso, podrían pertenecer directamente a esta sección, como en el caso de «La vida es sueño» y la edición de tres

16. Tienen también gran interés los textos de otros autores, que se conservan en el Archivo, en distinto estado, que aquí solo podemos enunciar, dejando su estudio para otra ocasión: de Santiago de Masarnau, «Real Conservatorio de Música María Cristina» y uno de los artículos sobre «Don Juan»; una parte de «Bellas Artes», de Valentín Carderera; el Soneto ya citado de De Laiglesia y Darrac; el de Alberto Lista, «En la muerte de Doña María Candelaria Casajus», la «Cantilena» de Gallardo y «Talía española» de Luis Usoz y Ríos. El «Fragmento traducido del Sitio de Corinto poema del célebre Lord Byron», «Por Telesforo de Trueba Cosío». El poema de Jacinto de Salas y Quiroga, «La muerte del bravo» — que parece una premonición exacta del caso de Campo AlangeDe Espronceda, La pata de palo» y «El Pelayo. Fragmentos». Entre los originales que finalmente no se publicaron en El Artista, además de alguna poesía de Pedro de Madrazo, se encuentra el manuscrito autógrafo de un relato de Zorrilla que quedó inédito: «Nuño Gimeno o La puerta del So», firmado por «José Zorrilla Moral». También se conserva el texto, de letra no identificada, de varias «Anécdotas» de menor interés, que son traducciones extraídas de la vida de Federico II de Prusia (pueden verse en Vie de Frédéric II, Roi de Prusse, t. IV. Vie privée et littéraire (Strasbourg/ Paris, 1788) y un artículo, «Farinelli», anónimo, que es traducción de la voz «Farinelli» de la Biographie Universelle de Michaud (Paris, 1815, t. 14, págs. 161-4).

Anales, 25, 2013, pp. 11-43 
comedias de Tirso de Molina aunque, como señalamos, no se les incluye bajo el marbete de Variedades, consta en los manuscritos que esa era la sección a la que, en principio, estaban destinados. Siempre se trata de sueltos o breves artículos sobre publicaciones recientes, crónica teatral y otras referencias de actualidad que, salvo excepciones, aparecen en todas las entregas, como era común en las secciones correspondientes de las publicaciones periódicas de la época.

A través de los manuscritos conservados también se puede comprobar la estrecha colaboración entre Ochoa y Campo Alange; de cómo llevan entre ambos el peso de la revista y comparten, a veces materialmente, en la misma hoja, la construcción de las Variedades. Ambos autores tienen un papel similar en cuanto al número de Variedades redactadas y el relieve de los temas tratados, siempre de gran interés y trascendencia para la labor de El Artista, dentro de los límites de este género de escritos.

Otro aspecto importante de la actividad de Campo Alange en El Artista es el de los avisos para la imprenta que aparecen en varios de los originales manuscritos. Aunque a lo largo de la vida de El Artista, Ochoa sería el encargado de relacionarse con la imprenta en cuanto a los textos publicados en El Artista ${ }^{17}$, a través de las anotaciones en los originales, puede verse que, en estos primeros meses de 1835, es Campo Alange quien se ocupa de ello; sólo por excepción, aparece un aviso de Ochoa para la imprenta en el texto de una de sus colaboraciones (ACCA 66.092025). Según la documentación conservada, es siempre Campo Alange quien da a la imprenta las instrucciones de carácter general sobre las entregas de El Artista, además de hacerlo en sus propios textos. Los originales suelen ir en cuartillas escritas en orientación horizontal o vertical, que se doblan, cada original completo por separado, para entregarlas a la imprenta; en ocasiones, con una advertencia en el anverso de la última hoja, doblada en $8^{\text {old }}$, en que se señala el título de la colaboración, que puede consistir en una indicación acerca de su contenido — «Soneto», o, «Resto del artículo de Carderera»—, o la indicación genérica «Para el Artista». Así, entre otros ejemplos, en el anverso de la última cuartilla doblada en $8^{\circ}$, anota, en vertical: «Va el final de Amberès/ Es preciso procurar traer las pruebas mañana jueves por la tarde $\mathrm{p}^{\mathrm{a}}$ tener tpo de hacer las correcciones necesarias

17. De lo que queda algún testimonio, como la deferente misiva que dirige a Masarnau (Simón Díaz 1946, pág. 30).

18. En una ocasión esta función la cumple una página impresa de El Artista de un $n^{\circ}$ anterior: la $\mathrm{n}^{\circ} 51$, correspondiente a la entrega $5^{\text {a }}$ del domingo 1 de febrero de 1835 , que es utilizada para anotar al dorso: «Original del Artista / Núm. 9 del Domingo $1^{\circ}$ de Marzo de 1835» (ACCA 65.0025002). 
// $\mathrm{P}^{\mathrm{a}}$ el Artista/» (ACCA 66.089044). También, en una ocasión al menos, se ocupa de la rectificación de erratas: «Erratas del número anterior» (ACCA 66.092131), así como avisos que se incluyen en Variedades e índices de la entrega correspondiente.

En las páginas siguientes, siguiendo el orden de las entregas, señalaremos la participación de Campo Alange en los textos no firmados, indicando los aspectos de mayor relieve, especialmente, en los casos en que se combina su participación con la de Ochoa; citando también los que aparecen con su firma, para dar una idea completa de la actividad de Campo Alange en cada número de los tres primeros meses de El Artista. Los textos de las Variedades que se conservan en el Archivo, tanto de Campo Alange como de Ochoa, se transcriben en el Anexo como aparecen en El Artista, para dar agilidad a la enumeración de las colaboraciones sin excesivas citas.

\section{Entregas $1^{\mathrm{a}}$ a $3^{\mathrm{a}}[4,11$ y 18 de enero de 1835]}

No se conserva en el Archivo ningún original de los textos no firmados de las tres primeras entregas de El Artista, correspondientes a los domingos 4, 11 y 18 de enero de 1835. En la $1^{a}$ entrega (4-1-1835), el único texto de este carácter es el editorial con que se inicia la publicación. El artículo, programático, aparece sin firma, pero está atribuido a Ochoa en el «Índice del Tomo Primero» de El Artista. Por lo demás, como se ha indicado, de la entrega $1^{\text {a }}$ solo se conserva en el Archivo el comienzo de los «Recuerdos del sitio de la ciudadela de Amberes», de Campo Alange. En la 2a entrega (11-1-1835), en que se publica el Fragmento II de los «Recuerdos de Amberes», se inicia la sección Revista Semanal. Variedades, con noticias actuales ${ }^{19}$; la primera parte del marbete sería suprimida en los siguientes números, quedando solo en Variedades, más comprehensivo. Aunque no se conserva el original de estas

19. En la primera entrada, se anuncia, después de un breve comentario de la comedia de Scribe, Las desdichas de un amante dichoso, que no se van a tratar en adelante obras extranjeras, de modo coherente con los propósitos de El Artista (I, 24) —para esta comedia, como, en general, para las obras dramáticas de este periodo (Menarini 2010)—. Se hace también una referencia, elogiosa en conjunto, al estreno del momento: El hombre gordo, de Bretón de los Herreros. En la segunda entrada aparece el tema obligado de los bailes que se están celebrando, que El Artista trata con mayor sensibilidad que otros periódicos, haciéndose eco, en las mismas líneas, de la tragedia que supone la guerra. Terminan las Variedades con una referencia a la estampa litografiada que se entrega con el ejemplar. Sobre el teatro de Bretón en estos años, es de gran utilidad la reciente obra de Ana Isabel Ballesteros Dorado; en este caso (Ballesteros Dorado 2012, t. II, págs. 188-197).

Anales, 25, 2013, pp. 11-43 
Variedades pueden atribuirse con seguridad a Ochoa, ya que Campo Alange está en Vitoria, a punto de entrar en combate.

En la $3^{a}$ entrega de El Artista (18-1-1835), no existe la sección correspondiente a Variedades. De Campo Alange, hay dos colaboraciones: la importante y conocida proclama «A la Aristocracia española», como artículo de fondo, firmado excepcionalmente con las iniciales completas - «El C. de C. A.»-, del que existe original en el Archivo (ACCA 66.092100-115), y el Fragmento III de los «Recuerdos del sitio de la ciudadela de Amberes».

\section{Entrega $4^{\mathrm{a}}$ [25 de enero de 1835]}

La entrega $4^{\text {a }}$ de El Artista (25-1-1835) se abre con una nota, sin título (I, 37); aunque aparece como «Advertencia», en el «Índice del Tomo Primero». Se trata de un pequeño artículo de carácter editorial, que se ha atribuido a Ochoa (Randolph 1966, pág. 22), pero que corresponde a Campo Alange, como puede comprobarse gracias al manuscrito autógrafo conservado (ACCA 66.092008-9). Es el texto no firmado de mayor relevancia que se conserva como original de Campo Alange en cuanto a las tareas de dirección y fundación de El Artista, ya que en él, Campo Alange se reconoce como su fundador al hacer referencia a la finalidad de la publicación; incluyéndose en «nuestro intento» -implícitamente con Ochoa y Madrazo-, a propósito de los principios que regirán la admisión de «Comunicados» en la revista:

Al fundar el Artista, no ha sido otro nuestro intento que el de despertar en nuestra patria el gusto a las bellas artes, que tanto ennoblecen a los que las cultivan y que entre nosotros son el objeto de una indiferencia harto dolorosa; y abrir al mismo tiempo una tribuna en que puedan emitirse libremente todas las opiniones en punto a las materias que pertenecen a nuestro dominio [...] $(\mathrm{I}, 37)$.

En esta entrega, $n^{\circ} 4$, además de la reseña de la traducción de «El último día de un reo de muerte», de Victor Hugo (I, 40), que Campo Alange aprovecha para hacer una decidida contribución a la batalla por el Romanticismo, se incluye una colaboración no firmada de Campo Alange con el título «La vida es sueño», sobre la representación de la obra de Calderón que corresponde al jueves 22 de enero de $1835^{20}$. En el manuscrito autógrafo de Campo Alange, la crónica teatral de La vida es sueño no aparece con ese título sino, directamente, debajo del epígrafe «Variedades» (ACCA, 66.092003-7), seguida de otra «variedad», también de Campo Alange, parcialmente tachada, sobre la pieza

20. Teniendo en cuenta el anuncio del Diario de Avisos de Madrid (22-1-1835), que sólo anota otra representación, cercana, en el siguiente mes de febrero (2-2-1835). 


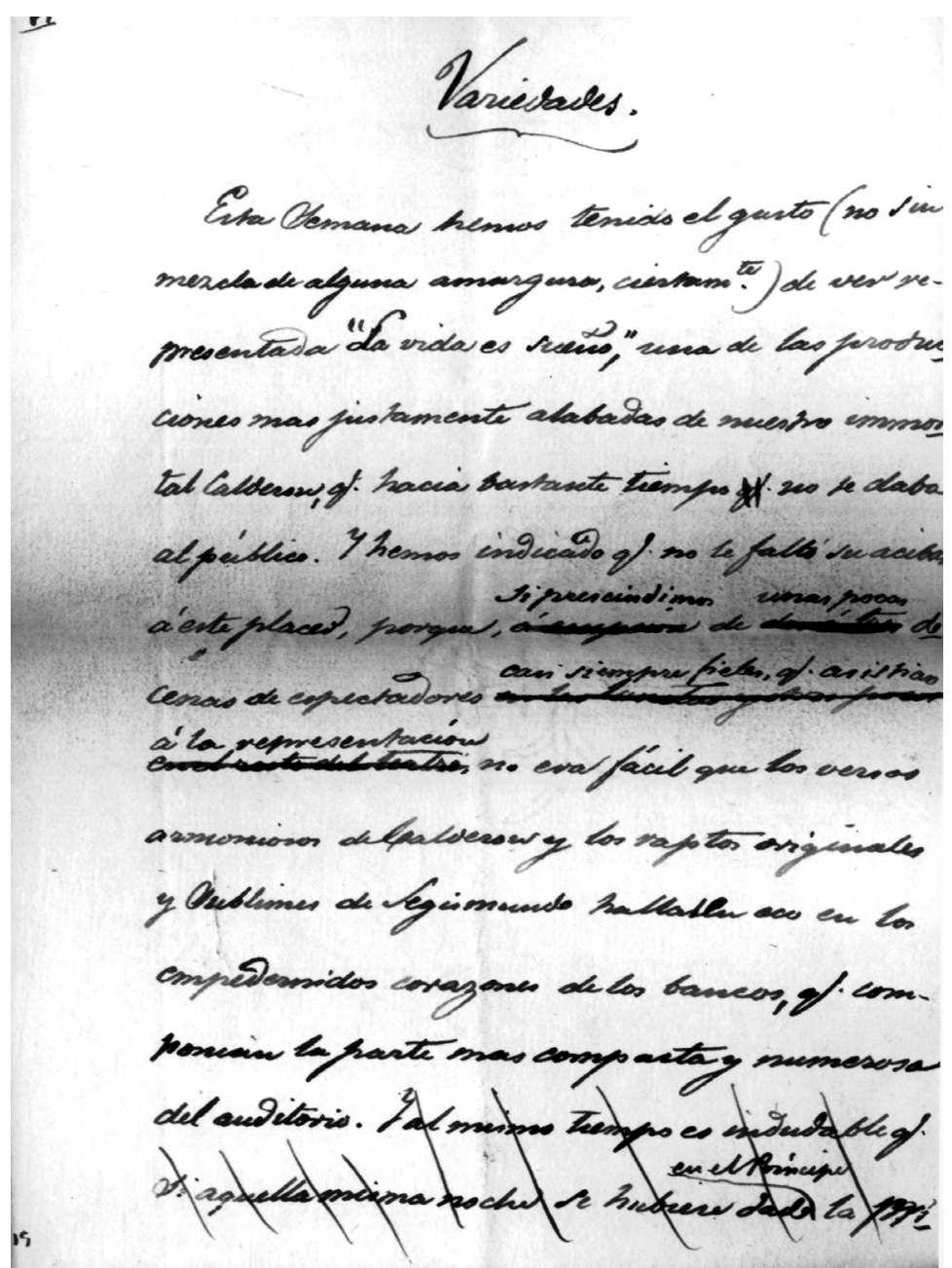

Ms. autógrafo de José de Negrete, conde de Campo Alange (ACCA, 66.092008). El Artista. Entrega 4ª [25 de enero de 1835], I, 48.

de Scribe, Bertrand y Raton o El arte de conspirar ${ }^{21}$, que no llegó a publicarse en El Artista. Seguramente, por este motivo se cambia el título, pasando de

21. La obra de Eugène Scribe, Bertrand y Raton ou L'art de conspirer [1833], se encuentra, como "Arte de conspirar», en la relación de «Libros entregados al Sr. D. Eugenio Ochoa», a la muerte de Campo Alange (ACCA 66.004). La traducción es de Larra, como Ramón de Arriala; no aparece nombre de traductor en el Archivo.

Anales, 25, 2013, pp. 11-43 
Variedades a «La vida es sueño», al quedar la crónica teatral de la representación como único tema.

Aunque breve, se trata de un interesante artículo que forma parte de una de las principales tareas de Campo Alange en El Artista, el estudio de la vertiente teatral del Romanticismo. En este caso, en el marco esencial del teatro antiguo español, en concreto, de Calderón, a propósito de una representación, por lo demás, ocasional dentro de la programación de los teatros. Campo Alange, aprecia la oportunidad de ver puesta en escena la obra «de nuestro inmortal Calderón», a pesar de los problemas que acarrean las representaciones de obras de los clásicos españoles, destacando el esfuerzo de la empresa (I, 48). Este breve homenaje a Calderón hecho por Campo

Alange, precede exactamente al estudio de Ochoa, titulado «Calderón», que, como artículo inicial, aparece en la siguiente entrega, $\mathrm{n}^{\circ} 5$, al que acompaña la estampa litográfica de su retrato, por Federico de Madrazo; siguiendo la idea de El Artista de mantener una cierta relación entre los contenidos entre sí y con la oportunidad de los mismos.

\section{Entrega $5^{\mathrm{a}}$ [1 de febrero de 1835]}

Campo Alange interviene activamente en el $\mathrm{n}^{\circ} 5$ de El Artista, que cuenta con dos colaboraciones suyas: la primera parte del artículo titulado «Teatro», en la sección «Literatura», y el Fragmento IV de «Recuerdos del sitio de la ciudadela de Amberes» (I, 52-55 y 59-69, respectivamente). No se conserva en el Archivo el original de la nota que cierra el número, «Bailes de Máscaras», ni del suelto en que se aclara que por ser demasiado largo el artículo dedicado al Real Museo, no acompaña a la estampa que se distribuye sino que se reserva para el próximo número $(\mathrm{I}, 60)$; por lo que nada puede decirse sobre la autoría de estos textos.

\section{Entrega $6^{\mathrm{a}}$ [8 de febrero de 1835]}

En el $n^{\circ} 6^{a}$ de El Artista, en que aparece la segunda parte del artículo «Teatro», de Campo Alange, la sección Variedades está formada por 10 entradas, un número mayor de lo habitual, sobre interesantes aspectos de la actualidad cultural que, como en otras ocasiones, coinciden, en parte, con las noticias y comentarios de los demás periódicos madrileños. En el Archivo de los condes de Campo de Alange se conservan las Variedades de este $\mathrm{n}^{\circ} 6$, excepto las tres primeras entradas y las primeras líneas de la $4^{a}$, que aparece en $5^{\circ}$ lugar, en el texto impreso, sobre los bailes anteriores al Carnaval. Está escrita, junto con la siguiente entrada, que trata del beneficio de Concepción Rodríguez, en una 
cuartilla numerada con «2)», de letra de Ochoa. Seguramente, las entradas anteriores y las primeras líneas de la $4^{\mathrm{a}}$ estaban escritas en una misma cuartilla, la $\mathrm{n}^{\circ}$ «1)», que se ha perdido (ACCA 66.92032).

Aparte de los temas tratados, las Variedades de este $\mathrm{n}^{\circ} 6$ tienen un interés particular porque, a través de los manuscritos autógrafos, se puede comprobar que pertenecen a Ochoa y a Campo Alange, aunque se publican todas ellas de manera seguida en la correspondiente sección. Como puede verse en el «Anexo», Ochoa escribe las entradas relativas al «beneficio de la primera actriz española» (ACCA 66.092032) —Concepción Rodríguez, cuyo beneficio (31-1-1835), fue terriblemente conflictivo-; a los bailes, poco concurridos (ACCA 66.092032), a la Puerta del Sol de Toledo (ACCA 66.92076) y al próximo beneficio de Guzmán, en que se pondrá en escena El Diablo Predicador (ACCA 66.092031); así como noticias de París sobre la prensa litográfica presentada en la Exposición del año anterior (ACCA 66.092012).

Por su parte, pertenecen a Campo Alange tres entradas, intercaladas con las de Ochoa: sobre las candilejas desagradablemente humeantes de El Príncipe los días en que se representa la ópera Guillermo Tell (ACCA 66.092001); a propósito de las decoraciones que Blanchard está pintando para la primera representación de Don Álvaro o La fuerza del sino, con palabras de elogio para el autor y la empresa, que se arriesga con un drama original compuesto según las modernas doctrinas literarias —es decir, plenamente romántico (ACCA 66.092001)—; y sobre los progresos del grabado en madera en Inglaterra y Francia (ACCA 66.092012).

Los manuscritos de estas Variedades presentan otra importante peculiaridad: en el anverso de una de las cuartillas, escritas en horizontal por Ochoa - correspondiente al texto sobre la Puerta del Sol de Toledo-, aparecen, escritas en vertical, por Campo Alange, en la octavilla que resulta de doblar las cuartillas correspondientes al mismo envío, una serie de instrucciones para la imprenta que muestran la realidad viva de El Artista como publicación periódica; correcciones de última hora, premura de tiempo y, en este caso, el ir y venir de las pruebas de imprenta:

En lugar de Revista Semanal, pongase Variedades. Dentro de media hora irán algunas mas $\mathrm{p}^{\mathrm{a}}$ completar el $\mathrm{n}^{\mathrm{o}}$.

- Si pueden enviar las pruebas de las $\mathrm{q}^{\mathrm{e}}$ ayer se dieron, $\mathrm{q}^{\mathrm{e}}$ lo hagan al instante.

- Del artículo de Literatura tampoco seria malo enviar las $2^{\mathrm{a}}$ ayer no vinieron $=$ porq $^{\text {e }}$ en el último $\mathrm{n}^{\mathrm{o}}$. fueron muchas mentiras (ACCA 66.092077). 


\section{Entrega $7^{\mathrm{a}}$ [15 de febrero de 1835]}

No se conservan en el Archivo las colaboraciones de Campo Alange que se publican en el $n^{\circ} 7$ de El Artista — «Fuensaldaña», ni los Fragmentos V y VI de los «Recuerdos de Amberes»—; tampoco el original del breve artículo «Teatro de la Cruz. Función extraordinaria á beneficio del señor García Luna» (I, págs. 82-3), del que, por tanto, se desconoce la autoría. Sí se conserva, como señalamos, el original del «Comunicado. Sobre el revoque de las casas» (I, 83-4) (ACCA 66.092116-23).

\section{Entrega $8^{\text {a }} 22$ de febrero de 1835]}

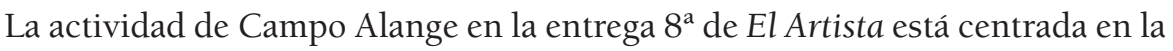
refutación del artículo publicado en el Eco del Comercio, «Del nuevo género de dramas introducido en Francia» (14-2-1835), en que se pone en tela de juicio la validez del moderno teatro francés que, sin duda, defendían los redactores de El Artista - al menos, a «algunas partes» del artículo, como prudentemente se especifica en el no 10 de El Artista (I, 120)—. Frente al ataque del Eco, será Campo Alange el que defienda el concepto del Romanticismo actual contra las ideas vertidas en un periódico contrario en algunos aspectos ${ }^{22}$. En este número, no hay Variedades como tal sección, sino solamente dos notas, cuyo original no se conserva en el Archivo: una de ellas, sobre la Ínsula Barataria, a propósito de la estampa correspondiente que se reparte con la entrega; otra, muy breve, sobre la imposibilidad de insertar en este número la reseña de las Poesías de Juan Bautista Alonso, tema obligado de los periódicos de esos días, avisando de que se hará en el próximo.

\section{Entrega $9^{\mathrm{a}}$ [1 de marzo de 1835]}

Por contraste con la escasa información que puede darse de la entrega $\mathrm{n}^{\circ} 8^{\circ}$, en la entrega $9^{a}$ de El Artista, además del Fragmento VII y último de los «Recuerdos del sitio de la ciudadela de Amberes» (ACCA 66.08923-44), hay varios textos no firmados de Campo Alange y Ochoa que se han podido identificar gracias a los manuscritos conservados: el breve artículo de Campo Alange sobre la edición de tres comedias de Tirso de Molina y las diversas entradas de la sección de Variedades, en que se entremezclan la letra de Ochoa y la de

22. El Eco del Comercio había elogiado a El Artista el mismo día (31-12-1834) en que inserta el anuncio de su salida, similar al que aparece en La Revista Española (30-12-1834); por otra parte, todavía en esta época, poco antes de que Antonio Gil y Zárate dejara de ser redactor del mismo, en abril de 1835, no se había radicalizado en sus ideas políticas tanto como ocurrió después (Ochoa 1840, pág. 25). 
Campo Alange, dejando ver una vez más la unión y estrecha colaboración en las tareas de El Artista que existía entre ambos.

El autógrafo de Campo Alange sobre la publicación de tres comedias de Tirso en Talía Española, presenta, de su letra, el encabezamiento « $P^{a}$ Variedades» (ACCA 66.092132-3). En la versión impresa, desaparece el encabezamiento y el artículo comienza directamente (I, 107), insertado entre dos textos de Santiago de Masarnau: una nota en que Masarnau contesta a la impugnación que se le había hecho en El Observador del 23 de febrero - «el 23 del corriente», cuando escribe Masarnau, aunque aparece publicado el 1 de marzo-, y un breve artículo titulado «Real Conservatorio de Música María Cristina» (I, 107 y 107-8, respectivamente).

A continuación de este último artículo sobre el Real Conservatorio, aparece la sección Variedades, con una primera entrada debida a Campo Alange (ACCA 66.092014), en que, con un presagio de los temas que estarán presentes en Pamplona y Elizondo, trata del deseo general de olvidar la guerra divirtiéndose todo lo posible; así como de la conveniencia de prolongar la temporada teatral con el permiso para que pueda haber representaciones en Cuaresma (I, 108). También de Campo Alange, se conservan en el Archivo dos entradas correspondientes a estas Variedades que, quizá por problemas de espacio, se suprimen en la versión impresa. La primera, en la misma cuartilla que la anterior entrada sobre las diversiones del Carnaval, da cuenta del baile que ofreció el «Sr. Ministro de Hacienda» —el conde de Toreno—, al que asistió la Reina Gobernadora (ACCA 66.092014); en la segunda trata de una próxima mejora de la tipografía de El Artista (ACCA 66.092074). En el manuscrito aparecen entremezclados, en el mismo folio doblado en cuatro, dos textos de Ochoa y dos de Campo Alange, con algún retoque de Ochoa. El orden en que aparecen en el folio es el siguiente: a) el aviso, escrito por Ochoa, de un accidente imprevisto por el que no pueden dar en ese número las dos estampas habituales, que lleva en el margen superior izquierdo la anotación «Penúltima», aunque en el texto impreso aparece en último lugar; b) el «Índice» de la entrega, de letra de Campo Alange, que no coincide enteramente con el del ejemplar al que se refiere y que, por otra parte, no llegó a publicarse en la versión impresa ${ }^{23}$; c) una nota de Campo Alange con el anuncio de una nueva fundición de breviario que esperan para El Artista, con la anotación en el margen superior izquierdo de «Última Variedad»; entrada que, finalmente, no llegó a publicarse; y d), en la mitad inferior del folio, la entrada escrita

23. En cambio, en el texto impreso aparecen, al final, unas líneas con las «Erratas del número anterior» que, como indicamos, están escritas por Campo Alange (ACCA 66.092131)

Anales, 25, 2013, pp. 11-43 
por Ochoa, dando cuenta de que, por «cartas de Roma», saben que ya está concluida la estatua de Cervantes ejecutada por el escultor Antonio Solá, dispuesta para venir a España (I, 108) (ACCA 66.092074).

\section{Entrega $10^{\mathrm{a}}$ [8 de marzo de 1835]}

De la entrega $10^{\text {a }}$ de El Artista, en que Campo Alange comienza a publicar su novela breve Pamplona y Elizondo, no han quedado en el Archivo ninguno de los dos textos no firmados que se insertan al final de la entrega, con función equivalente, aunque sin el título, de Variedades; por lo que se desconoce su autoría.

\section{Entrega $11^{\mathrm{a}}$ [15 de marzo de 1835]}

Sin embargo, la siguiente entrega, $\mathrm{n}^{\circ} 11$, en que termina Pamplona y Elizondo, ofrece otro testimonio excepcional de la colaboración de Campo Alange y Ochoa en este tipo de textos ya que, al haberse conservado el manuscrito de las Variedades de este número, se puede identificar fácilmente la autoría de cada uno de ellos a través de su letra. En la publicación impresa, estas Variedades se presentan en dos grupos, entre los que se intercala el soneto remitido por Francisco de Laiglesia y Darrac «En la muerte del general Don Manuel Freire ${ }^{24}$. Las tres «variedades» del primer grupo, sobre noticias enviadas desde Roma, se conservan en el Archivo de letra de Ochoa (ACCA 66.092024-5). En el segundo grupo, que sigue al soneto de De Laiglesia, aparecen dos entradas, debidas, cada una de ellas, a Campo Alange y a Ochoa. En el manuscrito correspondiente a este grupo, se alternan la letra de Campo Alange y la de Ochoa; comenzando por un aviso a la imprenta de Campo Alange que, obviamente, no se recoge en el texto impreso: «Es preciso q vaya la $1^{\text {a }}$ variedad, aunq sea en letra chica, y si cabe la $2^{\mathrm{a}} \mathrm{q}$ ocupará un par de renglones, tampoco será malo» (ACCA, 66.092002). Seguidamente, aparece la que debería ser la $2^{a}$ «variedad»: un suelto de letra de Ochoa, sobre el próximo estreno de Don Álvaro, que se inserta al final de las Variedades en el texto impreso: «El próximo domingo se dará la $1^{\text {a }}$ representación de D. Alvaro o la fuerza del Sino» (I, 132). En el manuscrito original aparece a continuación el texto que debe insertarse en primer lugar en este segundo grupo de entradas; grupo que, efectivamente, se imprime en letra mucho menor que el anterior grupo de

24. En el propio manuscrito de De Laiglesia, Ochoa escribe de su mano la nota que antecede al texto impreso: "Nos ha sido remitido el siguiente Soneto, que nos apresuramos á ofrecer al público, en atención á la ilustre persona á quien lo dirije tan dignamente su autor» (ACCA 66.086001). 


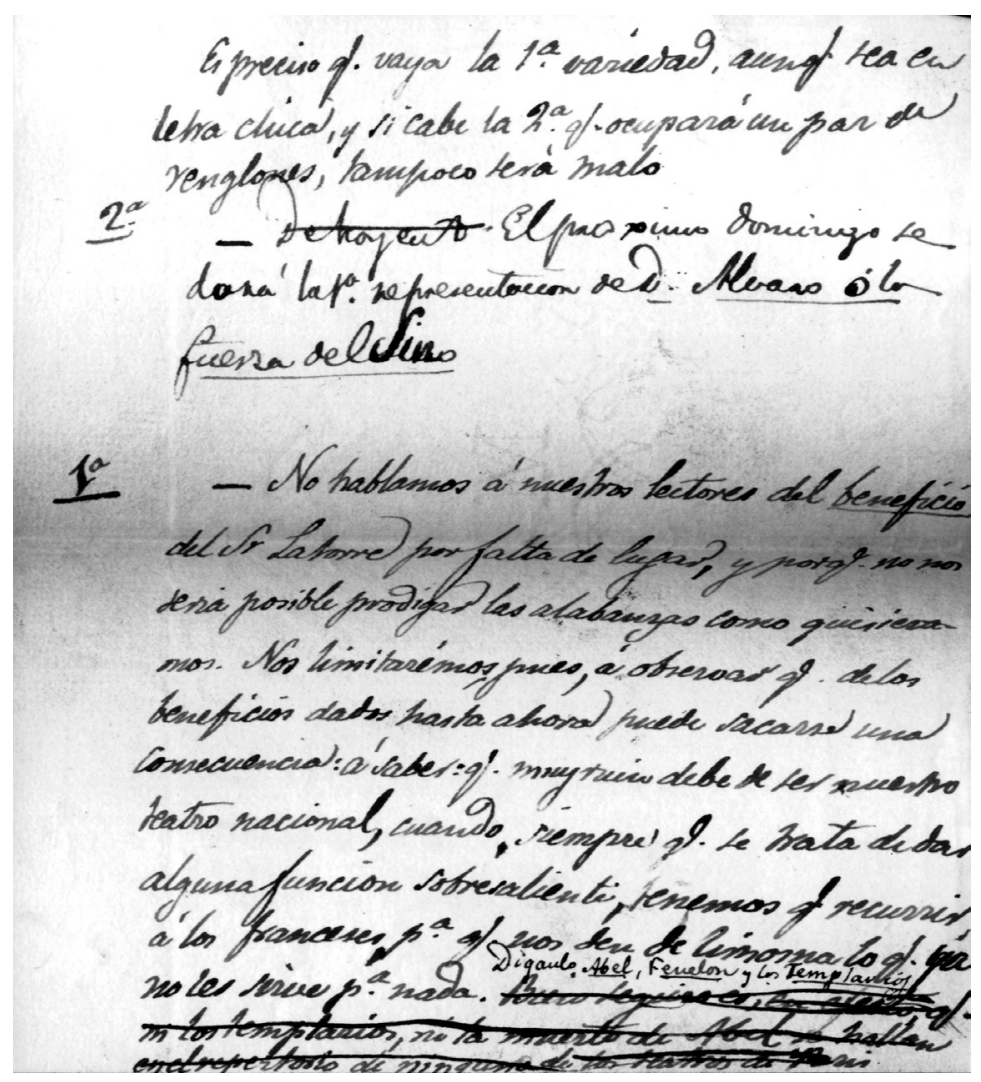

Ms. autógrafo de José de Negrete, conde de Campo Alange, y de Eugenio de Ochoa (ACCA, 66.092002). El Artista. Entrega 11 ${ }^{\mathrm{a}}$ [15 de marzo de 1835], I, 132.

Variedades e igual a la utilizada para el «Soneto». El texto de la última entrada, sobre el beneficio de Carlos Latorre, está escrito por Campo Alange, con algunas correcciones de Ochoa que reducen la extensión de la última frase, seguramente por razones de espacio (ACCA, 66.092002).

\section{Entrega $12^{\mathrm{a}}$ [22 de marzo de 1835$]$}

La entrega $12^{a}$ se cierra con una «Crónica de teatros», no firmada, cuyo original se conserva en el Archivo. Consta de varias entradas que, en principio, estaban pensadas como Variedades, según el encabezamiento del manuscrito, en que se lee, de mano de Campo Alange, «Variedades» [tachado] y, debajo, «Crónica de Teatros» (ACCA 66.092019-21). Las dos primeras entradas de 
la «Crónica», están escritas por Campo Alange. La primera trata de noticias recientes acerca de algunos actores, en plena gestación de los contratos para la nueva temporada teatral. La segunda entrada es la conocida nota sobre el estreno de Don Álvaro ese mismo día, del que Campo Alange promete hacer un análisis detenido: «Esta noche se dará definitivamente la primera representación de D. Álvaro, o la fuerza del Sino, drama en cinco jornadas, en prosa y verso, de cuyo éxito hablaremos a nuestros lectores [...] (I, 144)». Las otras dos entradas que completan la «Crónica de Teatros» están escritas por Ochoa, en una cuartilla distinta a la utilizada por Campo Alange (ACCA 66.092022). En la primera entrada, Ochoa da cuenta de que se les ha asegurado que en el próximo mes de abril se estrenará el drama de Jacinto de Salas y Quiroga, Alén Ferrando o El Cruzado; en la segunda, comenta con elogio el próximo estreno de otra pieza española, titulada Alfredo — se trata del drama de Joaquín Francisco Pacheco- $(\mathrm{I}, 144)^{25}$.

\section{Entrega $13^{\mathrm{a}}$ [29 de marzo de 1835 ]}

Finalmente, de la entrega $13^{\text {a }}$ de El Artista (29-3-1835), aunque, casualmente, queda una hoja impresa suelta, no se conserva en el Archivo ningún manuscrito de los originales de los textos publicados; seguramente, por el traslado del lugar de redacción ante la inminente partida de Madrid de Campo Alange. La entrega tiene una estructura distinta de la habitual. Se inicia con el artículo de José de Madrazo, titulado «Pintura», en que polemiza con Campo Alange a propósito de un episodio de Pamplona y Elizondo, seguido de la «Contestación» al mismo por parte del propio Campo Alange. Ambos artículos son más extensos de lo acostumbrado en su caso, como corresponde a la importancia de los textos y de sus respectivos autores. El siguiente artículo es la conocida y relevante reseña escrita por Campo Alange sobre el estreno de Don Álvaro o la fuerza del Sino. La entrega se cierra con una breve nota en la última página, en cuerpo mucho menor, que avisa del cumplimiento de la promesa de publicar los retratos de los principales artistas y literatos, dando en ese número el de

25. Alfredo se estrenó el 23 de mayo de 1835, con un desconcierto general que analizó Piero Menarini en un innovador estudio (Menarini 1998). A pesar de que El Artista incluye «Una escena de Alén Ferrando», el drama fue reprobado para su estreno, como se comenta en una dura nota previa al texto de Salas, firmada excepcionalmente Federico de Madrazo - menos implicado vida teatral- «Dos palabras sobre el Alen-Ferrando del sr. Salas» (III, 128-130). Grimaldi, al que Madrazo alude como «señor de G.», tuvo un papel decisivo, como es sabido, en la escena madrileña de estos años (Gies 1988, Caldera 2001, entre otros estudios de estos autores). Para una breve aproximación a Salas, (Rincón Calero 2010). 
Martínez de la Rosa, cuya noticia biográfica se deja para la siguiente entrega $(\mathrm{I}, 156)^{26}$.

El recorrido por los manuscritos relativos a El Artista que se conservan en el Archivo de los condes de Campo de Alange muestra la riqueza y novedad del fondo, y adelanta lo que, en futuros trabajos, se estudiará con detenimiento. Gracias a la identificación de la autoría de los textos no firmados publicados en los tres primeros meses de El Artista, queda de manifiesto la participación de José de Negrete, V conde de Campo de Alange, en aspectos desconocidos hasta ahora; más allá de sus importantes colaboraciones firmadas, ya conocidas. La identificación individuada de los textos de Campo Alange y de Eugenio de Ochoa, a través de los manuscritos autógrafos, revela también la estrecha colaboración entre ambos; la labor compartida y única de dirección de El Artista. A su vez, en los avisos a la imprenta, se desvela la implicación de Campo Alange en otros aspectos editoriales de la revista, como la cuidada atención a la perfección formal de cada número de El Artista.

Si con El Artista, la historia del Romanticismo español se vio decisivamente influida, y, en su caso, la literatura española en su conjunto, debe reconocerse la trascendencia de la tarea de sus redactores, tanto en el trabajo de mediación que efectuaron en relación con el Romanticismo como en sus propias obras de creación y sus ideas literarias. A pesar de la brevedad de su vida, la labor del conde de Campo Alange corresponde, por tanto, a la de uno de los autores de mayor relieve, dentro del Romanticismo, en el curso de la historia literaria de España. La calidad de las creaciones de Campo Alange y la crítica que desarrolla en El Artista así lo había ya conceptuado. Ahora, se ha podido probar que su actividad estaba más ligada todavía de lo que se conocía a la dirección y edición de la revista en sus comienzos; en los tres primeros meses de vida que marcaron la identidad de El Artista, para su público y para sus creadores.

\section{Bibliografía}

AlOnSO SEOANE, María José. 2001. «Sevilla en las revistas románticas. La colaboración del conde de Campo Alange en El Artista», en Rogelio Reyes Cano, Mercedes de los Reyes Peña y Klaus Wagner (eds.), Sevilla y la literatura. Homenaje al Profesor Francisco López Estrada, Sevilla, Universidad de Sevilla, págs. 343-354.

26. Los redactores señalan que este obsequio se dirige a Martínez de la Rosa escritor, autor de Edipo, de La conjuración de Venecia y otras obras valiosas; puntualización que, a pesar de la letra diminuta, al tratarse de una figura de tal transcendencia política, no pasó inadvertida a la prensa del momento.

Anales, 25, 2013, pp. 11-43 
Alonso SeOAne, María José. 2002. «La defensa del presente en El Artista y el nuevo canon romántico», La elaboración del canon en la literatura española del siglo XIX, II Coloquio de la Sociedad de Literatura Española del Siglo XIX (Barcelona, 20-22 de octubre de 1999). Barcelona: Universitat de Barcelona, págs. 11-26.

AlONSO SEOANE, María José. 2011a. «Larra y Campo Alange: relaciones personales y literarias», en Joaquín Álvarez Barrientos, José María Ferri Coll y Enrique Rubio Cremades (eds.), Larra en el mundo. La misión de un escritor moderno, Alicante, Universidad de Alicante, págs. 313-320.

Alonso SeOAne, María José. [2011b, en prensa] «La expresión de la individualidad romántica en los 'Recuerdos del sitio de la ciudadela de Amberes', del conde de Campo Alange», Congreso Internacional El Individuo y la Sociedad en la Literatura del Siglo XIX, ICEL19, 22, 23, 24 y 25 de noviembre de 2011, Santander.

AyAla Aracil, $\mathrm{M}^{\mathrm{a}}$ de los Ángeles. 2002. «La defensa de lo romántico en la revista literaria El Artista», en Piero Menarini (ed.), Los románticos teorizan sobre sí mismos. Actas del VIII Congreso del Centro Internacional de Estudios sobre Romanticismo Hispánico (Saluzzo, 21-23 de Marzo de 2002). Romanticismo 8. Bologna, Il Capitello del Sole, 2002, págs. 35-42.

BAllesteros Dorado, Ana Isabel. 2012. Manuel Bretón de los Herreros: más de cien estrenos en Madrid (1824-1840), Logroño, Instituto de Estudios Riojanos, 2 vol.

CALDERA, Ermanno. 2001. El teatro español en la época romántica, Madrid, Castalia. Calvo Serraller, Francisco y Ángel GonzÁlez García. 1981. El Artista, Madrid, 1835-1836, Estudio preliminar y ed. facsimilar, Madrid, Turner.

Laffitte y Pérez del Pulgar, María. Condesa de Campo Alange. 1946. «Carta de don Eugenio de Ochoa con noticias literarias y políticas». Correo Erudito, IV, 29, págs. 18-21.

Ferri Coll, José María. 2011. «Las ilustraciones de El Artista y la idea de lo romántico en la década de 1830», En Rodríguez Gutiérrez, Borja y Raquel Gutiérrez Sebastián (eds.), Literatura Ilustrada Decimonónica. 57 Perspectivas, PUbliCAN Ediciones, Universidad de Cantabria, 2011, págs. 243-50.

GIES, David Thatcher. 1988. Theatre and politics in nineteenth-century Spain: Juan Grimaldi as impresario and government agent, Cambridge, Cambridge University Press.

GonzÁlez López, Carlos, y MARTí AyxelÀ, Montserrat. 2007. «El mundo de los Madrazo», en AAVV, El mundo de los Madrazo: colección de la Comunidad de Madrid. Madrid (Comunidad Autónoma).

LÓPEZ SANZ, Genoveva Elvira. 2000. «Romanticismo frente a clasicismo en El Artista», Espéculo. Revista de estudios literarios, URL: http://www.ucm.es/info/especulo/numerol4/artistal.html 
LozAnO Miralles, Rafael. 1988. «La prosa narrativa en El Artista», en Ermanno Caldera (ed.), Romanticismo 3-4, Génova, págs. 171-174.

Mencos y MANSO DE ZÚÑIgA. 1952. Memorias de Don Joaquín Ignacio Mencos, Conde de Guenduláin 1799-882: Del manuscrito original que se conserva en el Archivo de los Condes de Guenduláin, en Pamplona. Corregido y preparado para la edición por José María Iribarren, Prólogo del Conde de Rodezno y notas de Don José María Azcona, Pamplona, Aramburu.

MenARINI, Piero. 1998. «Un drama romántico alternativo: Alfredo, de Joaquín Francisco Pacheco» en Luis F. Díaz Larios, Enrique Miralles (eds.), Del Romanticismo al Realismo, I Coloquio de la Sociedad de Literatura Española del Siglo XIX, Barcelona, Universitat, 1998, págs. 167-177.

MENARINI, Piero 2010. Al descorrerse el telón: catálogo del teatro romántico español: autores y obras (1830-1850), Rimini, Panozzo.

OсHOA, Eugenio de [1840]. Apuntes para una biblioteca de escritores españoles contemporáneos: en prosa y verso. Tomo segundo. París, Baudry, Librería Europea.

OchOA, Eugenio 1867. Necrópolis [1863], en Miscelánea de literatura, viajes y novelas, Madrid, Carlos Bailly-Bailliere, págs. 265-289.

RANDOLPH, Donald Allen. 1966. Eugenio de Ochoa y el romanticismo español, University of California Press, Berkeley.

RINCÓN CALERO, María Ester. 2010. «Periodismo y literatura en el romanticismo. El periódico literario «No me olvides» (1837-1838)», en Jorge Miguel Rodríguez Rodríguez, María Angulo Egea (coords.), Periodismo literario: naturale$z a$, antecedentes, paradigmas y perspectivas, Madrid, Fragua, págs. 71-87.

RODRÍGUEZ GUTIÉRREZ, Borja. 2011. «La voluntad iconográfica y aristocrática de El Artista», Revista de Literatura, vol. LXXIII, n 146 , págs. 449-488.

Rodríguez-Ponga y Salamanca, Pedro. 2012. «Negrete y Cepeda, José Agustín de», en AAVV, Diccionario Biográfico Español, t. XXXVII, Real Academia de la Historia, págs. 585-590.

ROMERO TOBAR, Leonardo. 1975. «Sobre censura de periódicos en el siglo XIX. Algunos expedientes gubernativos de 1832 a 1849», Homenaje a D. Agustín Millares Carlo, Las Palmas, I: 465-500.

SAltillo, Marqués del [Miguel Lasso de la Vega y López de Tejada]. 1931. «Un prócer romántico. El Conde del Campo de Alange», Boletín de la Biblioteca Menéndez y Pelayo, I, 1931, págs. 3-23.

SimÓn DíAZ, José. 1946. El Artista (Madrid, 1835-1836), Madrid, Consejo Superior de Investigaciones Científicas.

ZORRILlA, José. 1880. Recuerdos del tiempo viejo, Barcelona, Imprenta de los sucesores de Ramírez y $C^{\text {ía }}$.

Anales, 25, 2013, pp. 11-43 


\section{ANEXO}

Textos no firmados publicados en El Artista cuyos originales se encuentran en el Archivo de los Condes de Campo de Alange ${ }^{27}$

\section{1. [«Advertencia»] El Artista, no 4 (25-1-1835), I, 37}

Al fundar el ARTISTA, no ha sido otro nuestro intento que el de despertar en nuestra patria el gusto a las bellas artes, que tanto ennoblecen a los que las cultivan y que entre nosotros son el objeto de una indiferencia harto dolorosa; y abrir, al mismo tiempo, una tribuna en que puedan emitirse libremente todas las opiniones, en punto á las materias que pertenecen á nuestro dominio. Sentado esto, es evidente que siempre que hagamos la crítica de alguna obra o proyecto, hallarán acogida en nuestras columnas las observaciones de su autor, en el supuesto de que, como lo esperamos, se hallen expresadas en términos decorosos y sin amargura, como los que siempre emplearemos en nuestra censura. Asimismo entendemos no cargar con la responsabilidad de los artículos comunicados que insertemos, siempre que estos lleven la firma de su autor, como tenemos derecho de exigirlo cuando su contenido no se halle en completa conformidad con nuestras ideas. Del mismo modo que permitimos el ataque damos lugar a la defensa. De aquí resultará la discusión, y de la discusión nace casi siempre la verdad (ACCA 66.092008-9).

\section{2. [La vida es sueño] El Artista, $\mathbf{n}^{\circ} 4$ (25-1-1835) I, 48}

\section{LA VIDA ES SUEÑO}

Esta semana hemos tenido el gusto (no sin mezcla de alguna amargura ciertamente) de ver representada «La vida es sueño», una de las producciones más justamente alabadas de nuestro inmortal Calderón, que hacía bastante tiempo no se daba al público. Y hemos indicado que no le faltó su acíbar a este placer, porque, si prescindimos de unas pocas docenas de espectadores casi siempre fieles, que asistían a la representación, no era fácil que los versos armoniosos de Calderón y los raptos originales y sublimes de Segismundo hallasen eco en los empedernidos corazones de los bancos, que componían la parte mas compacta y numerosa del auditorio.

Acaso contribuya á esta frialdad el modo con que algunas veces se han puesto en escena nuestros antiguos dramas, es decir, con los trajes más rancios

27. Transcribo según el texto publicado en El Artista, actualizando ortografía y puntuación; la parte escrita por Eugenio de Ochoa va en cursiva. Excepcionalmente, corrijo erratas según el manuscrito correspondiente, justificándolo en nota. 
y descoloridos, las decoraciones más descascaradas, mohosas e inverosímiles, con una música que convida a un dulcísimo sueño y, finalmente, con el acompañamiento invariable de baile nacional y del gracioso y divertido sainete.

Mas para ser justos con la empresa, fuerza es confesar que «La vida es sueño» ha sido puesta en escena con más esmero que otras muchas. Las decoraciones son regulares: los trajes, aunque en punto a verdad histórica no pueden ofrecerse como modelos, asaz lucidos; y la comitiva del rey bastante numerosa. - Por lo que hace a la música, solo aconsejaremos al tambor y al clarín, que en las circunstancias arduas tocan al arma, que procuren que su toque se parezca algo menos al de la salida del toro a la plaza._- Los actores se han esmerado también algo más que en otras piezas antiguas. Luna ha tenido momentos muy felices. De Cubas diremos que sentimos que no haya hablado más, y de Galindo, por el contrario, que ha hablado demasiado; como, por ejemplo, en cierta ocasión en que, vitoreándole sus fieles vasallos no pudo reprimirse, y lleno de efusión, contestó a sus aclamaciones con un afectuosísimo igracias! que, para mengua del autor, no se hallaba en el texto ${ }^{28}$ (ACCA 66.092003-7).

\section{Variedades. El Artista, ${ }^{\circ} 6$ (8-2-1835) I, 71-2 29}

«-Cosa muy singular es que con dos traducciones de piezas francesas se haya solemnizado el beneficio de la primera actriz española. No parece, en verdad, sino que la literatura francesa tiene algún poderoso abogado cerca del tribunal sin apelación que dirige los teatros de esta capital. [ACCA 66.092032]

28. Corrijo como errata «teatro» por «texto» según el ms (ACCA 66.092007). En el manuscrito, solo se indica Variedades, sin título.

29. De las tres primeras Variedades, que transcribo aquí para facilitar su consulta, no se conservan originales en el Archivo, por lo que se desconoce su autoría. Las siguientes se deben a la pluma de Ochoa y de Campo Alange, alternativamente. «VARIEDADES. - Durante toda esta semana ha llamado mucho la atención del público la salida del excelente actor jubilado D. Joaquín Caprara, cuyo talento hubiéramos aplaudido de mejor gana en algún otro drama menos detestable que el de Fenelon o las Religiosas de Cambrai. - Es indudable que quedarán en el teatro del Príncipe los dos hermanos D. J. y D. F. Romea, y damos por ello a la empresa la más sincera enhorabuena. El primero de estos dos jóvenes actores nos parece digno de todo elogio, y lo mismo diríamos del segundo si renunciara de una vez a imitar en todo a su maestro en el arte que profesa. - Se asegura que quedará jubilada la Sra. Antera Baus; y, aunque hacemos justicia al mérito de esta actriz, nos parece, sin embargo, que es ya tiempo de que empiece a dormir sobre sus laureles» (I, 71). 
[-Los bailes de máscaras continúan sin interrupción en los teatros, en el café de Santa Catalina y en algunas casas particulares; el viernes empezaron en ${ }^{30}$ la Fontana de Oro. Pero, a pesar de las mejoras que en todos ellos se han introducido, el público los frecuenta poco; sin duda reserva su afición al baile, a los disfraces y a las intrigas para prodigarla en el alegre Carnaval. [ACCA 66.092032]

- Hemos observado que todas las noches que dan en el Príncipe la ópera de Guillermo ${ }^{31}$ Tell, cada candileja se convierta en una chimenea de la cual se desprende una manga de humo muy poco agradable, en verdad, al olfato; y, como en esta ópera se multiplica considerablemente el número de las luces, resulta que en breve rato se impregna la atmósfera del teatro de un tufo que, aunque profanos en el arte médico, nos inclinamos a opinar que no deberá de ser saludable para los pulmones enfermizos, ni de un efecto muy ventajoso para la tez delicada de nuestras damas.

- Se asegura que el Sr. Blanchard está pintando las decoraciones que se han de estrenar muy en breve en un drama en cinco jornadas, de uno de nuestros poetas más acreditados. Su título es, si no nos equivocamos, $D$. Alvaro o la Fuerza del Sino. No creemos inútil decir que este drama está compuesto en el sentido de las modernas doctrinas literarias: ni podemos menos de dar el parabién á la empresa por haber recibido en su repertorio una obra original española. Es una circunstancia que se presenta con tan poca frecuencia, que seria una injusticia no hacer mención de ella (ACCA 66.092001).

-Accediendo al deseo que nos han manifestado algunas personas de que diéramos, entre nuestras estampas, algunas que representaran monumentos nacionales, hemos creído que pocos podían llamar tanto la curiosidad como el de la Puerta del Sol de Toledo que damos en este número. Es esta puerta una especie de castillejo ovalado, puesto a la mitad de la subida de Zocodover; el carácter de su arquitectura, como indica la estampa, es del gusto árabe más exquisito. Pocos y no muy bien conservados son los vestigios que nos quedan del tiempo de los moros; pero, semejantes a la Puerta del Sol de Toledo, aun se ven esparcidos de trecho en trecho sobre el suelo de nuestra España, algunos airosos monumentos árabes; últimos centinelas, como ha dicho un gran poeta, de un campamento sepultado en eterno sueño. Tal vez publicaremos dentro de poco algunos detalles curiosos, que se ocupa en ir recogiendo por esos mundos de Dios, uno de nuestros colaboradores, sobre el origen del nombre con que se designa en el día esta antiquísima puerta (ACCA 66.092076).

30. Como se ha indicado, de estas primeras líneas de la «Variedad» correspondiente no se conserva el original en el Archivo.

31. Corrijo «Guillelmo» [ «Guglielmo»] por «Guillermo», según el ms (ACCA 66.092001). 
-Parece que se está ensayando para el beneficio del Sr. Guzmán la graciosísima y anónima comedia del Diablo Predicador. Mucho esperamos reírnos con las bellaquerías del P. Antolín si, como todos aseguran, desempeña este papel nuestro admirable Guzmán; nuestro Guzmán, que sería mucho más admirable si lograse desprenderse de ciertos malos resabios que le ha hecho contraer la costumbre de representar en ridículos dramas galo-hispanos papeles mas ridículos todavía. Sin el estímulo ${ }^{32}$, sin la emulación, el genio se marchita; el desaliento penetra en el alma del artista; al estudio sucede la rutina; a la verdadera sal cómica, la chocarrería que tanto gusta a la plebe; y el mejor actor, por fin, el de más talento, se convierte en una especie de purchinela.... Muy lejos está el Sr. Guzmán de hallarse en este caso, pero no ha sido en verdad porque hayan dejado de ponerse todos los medios posibles para lograrlo.

Este es el mayor elogio que puede hacerse de su talento (ACCA 66.092031).

-En la exposición del año pasado, en París, presentó Mr. Villeroi una prensa litográfica, a que da el nombre de Typolithográfica ${ }^{33}$. La piedra es cilindrica y se mueve por medio de la rotación sobre longitudes indefinidas con tal velocidad, que según asegura el inventor, pueden tirarse mil ejemplares por hora del objeto dibujado en la piedra. Esta prensa ocupa un espacio muy pequeño y cuesta lo mismo que las ordinarias (ACCA 66.092012).

-Increíbles son los progresos que de algunos años a esta parte ha hecho en Francia e Inglaterra el grabado en madera, infinitamente menos costoso que el grabado en acero y cobre, y elevado ya por algunos artistas a un grado de perfección de que no parecía susceptible. En la exposición de París del año 34 ha ocupado este ramo un lugar distinguido entre las artes liberales, y en el día a él se deben las lindísimas viñetas con que se adornan casi todas las obras de lujo (ACCA 66.092012).

\section{Variedades. El Artista ${ }^{\circ} 9$ (1-3-1835) I, 107}

«Ya se han puesto en venta las tres comedias del célebre Tirso de Molina que dan principio a la colección de dramas del antiguo teatro español, publicada por D. Agustín Duran; colección de que hicimos el debido elogio en nuestro número tercero, y que no podemos menos de recomendar de nuevo a nuestros lectores, tanto por la corrección del texto, cuanto por el lujo de la impresión que es en su género de lo más lindo que ha salido hasta el día de las prensas de esta capital. Nos han asegurado que el Sr. Durán tiene en su poder un número considerable de piezas inéditas de nuestros autores más justamente

32. Corrijo como errata «estimo» por «estímulo», según el ms (ACCA 66.092031).

33. Se trata de la «presse typolithographique» inventada por Villeroi.

Anales, 25, 2013, pp. 11-43 
celebrados, en cuya publicación hará un señalado servicio a la república de las letras. La Talía Española es una obra a que ninguna persona de gusto y que pretenda pasar por amante de las letras, puede dejar de suscribirse: es un monumento erigido a nuestra gloria nacional. ¿Llegará a tanto nuestra indiferencia que seamos causa de que quede incompleto? Nos lisonjeamos de que no. Lo único que sentimos es que no se tiren algunos ejemplares en papel vitela, para los que quisieran ver unos nombres tan gloriosos como los de Calderón, Lope y Tirso, rodeados de toda la gala de que es susceptible el arte de la librería.

Las tres comedias que están en venta son: La prudencia en la mujer, Palabras y plumas, y El pretendiente al revés. Cada una cuesta por ahora 4 reales pero, en llenándose la suscripción, se reducirá su precio a 3 reales. Se suscribe en Madrid en la librería de Cuesta, sin pagar nada adelantado (ACCA $66.092132-3)^{34}$.

\section{Variedades. El Artista n $^{\circ} 9$ (1-3-1835) I, 108 VARIEDADES}

A medida que se acerca que se acerca la cuaresma, va en aumento el ansia de diversiones del público, que ya casi raya en delirio. En vano intentan algunos acibarar esta alegría con funerales vaticinios; en vano lloran algunas familias en el retiro la pérdida de sus hijos malogrados en flor en las provincias del Norte; todos cierran los ojos al porvenir y solo piensan en lo presente, en el Carnaval con sus orgías, su desenfreno y su delirio. Y en verdad que dentro de tres días se enlutarán nuestras frentes con la ceniza bendita, y harto lugar nos dará la triste Cuaresma para gemir al contemplar los males presentes y al descubrir en el horizonte futuras calamidades. Por ahora, ya que no sea posible detener el curso del tiempo, solo debemos pensar en sembrarlo de cuantas flores nos sea posible; y en atención a esto preguntamos: ¿habrá teatros en Cuaresma? Se asegura que la empresa encargada de ellos ha representado al gobierno pidiendo que se le conceda esta gracia; y, si la naturaleza de nuestro periódico lo permitiese, creemos que no nos sería difícil demostrar la conveniencia de adoptar esta medida, ya se considere la cuestión bajo el interesante aspecto del interés general, ya bajo el de la moral pública (ACCA 66.092014).

- Por cartas de Roma sabemos que está ya concluida y expuesta al público la estatua del inmortal Cervantes, ejecutada por nuestro excelente escultor Don

34. Como se ha indicado, en el ms aparece, encabezando el texto, « ${ }^{a}$ Variedades» (ACCA 66.092132). 
Antonio Solá, director de los pensionados españoles y autor del famoso grupo de Daoíz y Velarde. Anunciamos con sumo placer que esta obra es en el día objeto de la admiración de todos los inteligentes, no solo por el mérito de la escultura sino por el exquisito trabajo de la fundición en bronce, la cual, nos aseguran testigos oculares, es un verdadero dechado en su género. Solo se espera la salida de algún buque para trasportar a Barcelona esta preciosa estatua, destinada a figurar en la plazuela de Sta. Catalina, frente al Estamento de Sres. Procuradores (ACCA 66.092074).

Por un accidente imprevisto no nos es posible dar en este núm. dos estampas como tenemos de costumbre; por lo tanto, en el núm. siguiente supliremos esta falta, dando una estampa además de la que corresponde (ACCA 66.092074).

\section{Variedades El Artista n ${ }^{\circ} 11$ (15-3-35) I, 132}

\section{VARIEDADES}

Nos escriben de Roma lo siguiente. = Es cosa muy triste ver la situación de los pensionados españoles; pues, habiendo ya hecho todos los estudios elementales de su arte y algunas copias con muy feliz resultado, se ven en la dura necesidad de no poder emprender los estudios que son consiguientes a los que ya han seguido ni servirse del natural para hacer algo de invención. Necesitarían para ello taller a propósito y aumento de pensión; y seguramente podría el gobierno cumplirles lo prometido, sin más que dar orden al gobernador de estos lugares píos españoles, para que se les aumente su asignación anual según lo establecido en los reglamentos (ACCA 66.092025).

-El célebre pintor Mr. Ingres, cuyo retrato, debido al pincel de Don Federico de Madrazo, vimos en la última exposición, se halla actualmente en Roma desempeñando las funciones de director de la Academia Francesa, en que sucede al pintor Horacio Vernet. Ciento cincuenta artistas acaban de dar una comida, con motivo de su partida a París, a este fecundísimo ingenio (ACCA 66.092025).

-El escultor D. Antonio Solá, director de los pensionados españoles en Roma, está terminando un grupo en mármol que representa una escena de la Degollación de los Inocentes, ejecutado por encargo del Sermo. Sr. Infante D. Sebastián (ACCA 66.092025).

[Nos ha sido remitido el siguiente Soneto, que nos apresuramos a ofrecer al público, en atención a la ilustre persona a quien lo dirige tan dignamente su autor. [ACCA 66.086001]

No hablamos a nuestros lectores del beneficio del Señor Latorre por falta de lugar y porque no nos sería posible prodigar las alabanzas como quisiéramos. 
Nos limitaremos, pues, a observar, que de los beneficios dados hasta ahora puede sacarse una consecuencia, a saber: que muy ruin debe de ser nuestro teatro nacional cuando, siempre que se trata de dar alguna función sobresaliente, tenemos que recurrir a los franceses para que nos den de limosna lo que ya no les sirve para nada. Díganlo Abel, Fenelon y los Templarios (ACCA 66.092025-24).

-El próximo domingo se dará la primera representación de D. Álvaro, o la fuerza del Sino (ACCA 66.092025-24).

\section{Crónica de teatros. El Artista, $\mathrm{n}^{\circ} 12$ (22-3-35) I, 144}

\section{CRÓNICA DE TEATROS}

Con harto sentimiento nuestro, hemos sabido que entre los actores nuevamente contratados, no se halla el señor Mate, uno de los más inteligentes y aventajados que poseían nuestros teatros y que nos ha robado por un año el de Cádiz.

No sabemos quién le reemplazará, pues harto escasos son en nuestra patria los actores capaces de desempeñar medianamente sus papeles en un drama un poco animado. Los jóvenes recién salidos del Conservatorio dan grandes esperanzas; pero al público no le bastan éstas, ni puede contentarse siempre con que le den en agraz un fruto que, bien sazonado, pudiera ser realmente sabroso. Se dice también que la empresa no quiere recibir al Sr. José Valero, y aun se susurra entre algunas personas asaz descontentadizas y atrabiliarias, que se trata de darnos una compañía de aficionados, acusación que creemos injusta y que ansiamos ver reducida a su verdadero valor. Sea como quiera, (y mal nos interpretará quien atribuya nuestras palabras a otra cosa que al interés general y a nuestro amor al arte), sea como quiera, repetimos, nos parece que resultarían al público y a los actores grandísimas ventajas de que cada uno de nuestros dos teatros dependiese de una empresa particular distinta; pues, como está en el día, es lo mismo que si tuviésemos un solo y único teatro. La rivalidad suele ser causa de grandes progresos; el monopolio los favorece muy poco, en general. El que la dirección de los teatros haya pasado de las manos de una corporación política a una empresa particular ha sido ya un gran paso hacía la deseada perfección. Otro nos queda todavía, que está claramente indicado por la esencia de las cosas y debe seguirse inmediatamente al primero (ACCA 66.092019-20).

-Esta noche se dará definitivamente la primera representación de D. Álvaro, o la fuerza del Sino, drama en cinco jornadas, en prosa y verso, de cuyo éxito hablaremos a nuestros lectores, haciendo al mismo tiempo un análisis 
de las bellezas y defectos que en él encontremos en nuestro próximo número. Se asegura que la empresa ha hecho desembolsos de consideración para adornarlo con todo el aparato teatral que exige su argumento, que en muchas partes puede considerarse como enteramente fantástico. Difícil sería no congratularse al ver una composición original ocupando por algunos días una escena invadida por muy modestas traducciones (ACCA 66.092021).

- Se nos asegura que en el próximo mes de abril veremos representado en esta corte un drama histórico original en cinco actos, cuyo título es Alen Ferrando o el Cruzado. Es obra del joven poeta D. Jacinto de Salas y Quiroga, ya conocido ventajosamente como uno de los defensores de la nueva literatura (ACCA 66.092022).

- Bien se conoce que estamos en una época santa y privilegiada. Solo así puede explicarse la inaudita prodigalidad de piezas españolas que se observa en nuestros teatros; además de las dos ya indicadas, se habla con grandes elogios de otra, titulada Alfredo, que no tardará en ponerse en escena (ACCA 66.092022) ${ }^{35}$.

Fecha de recepción: 05/04/2013

Fecha de aceptación: 19/09/2013

35. En ms, tach. «Variedades» antes de «Crónica de Teatros» (ACCA 66.092019).

Anales, 25, 2013, pp. 11-43 